\title{
Blood group polymorphism and possibilities of its utilization in selection of pigs
}

\author{
G.N. SERDJUK, O.A. LOZGACHEVA, I.V. KOZHUHAROVA, \\ N.A. PLETENKINA
}

All-Union Research Institute for Farm Animal Breeding and Genetics, Leningrad, U.S.S.R.

A comparative study of blood groups of the wild boar and present highly productive breeds of pigs was carried out. Monomorphism in the majority of the investigated blood group loci is typical for subspecies of the wild boar. The present highly productive breeds of pigs differ from their ancestors by great variety of allelic genes at the E, K, L and M blood group loci.

It has been established that selection for meat production indices increases the concentration of the Eedfhkmnp, $\mathrm{K}^{\mathrm{b}}$. L bdfi allelic genes in a population and selection for vitality increases the fre-

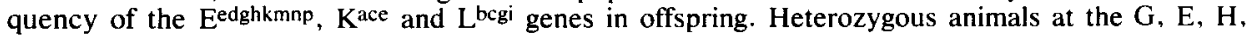
$\mathrm{K}$ and $\mathrm{L}$ blood group loci are more viable than homozygous ones.

We have come to the conclusion that blood groups may be successfully used for creation of lines and breed groups of farm animals as well as for increasing youngsters' viability under conditions of industrial technology.

\section{Correlation between pure-breeding and hybridization}

\author{
F.L. GARKAVY \\ Latvian Agricultural Academy, Ielgava, U.S.S.R.
}

For breeding highly productive crossbred animals and poultry using heterosis it is necessary to maintain a definite ratio between the number of purebred and crossbred animals. This ratio differs in different species of animals and poultry. The percentage of purebred animals range from $15-20$ in pig breeding to $80-90$ in horse breeding. Such a ratio is mainly determined by biological potentialities of dam stock reproduction and survival of female offspring until the first mating.

\section{The methods of breeding and the productive value of camels}

\author{
A. BAIMUKANOV \\ Kazakh research Institute of Karakul sheep breeding, Chimkent, \\ Kazakh Republic, U.S.S.R.
}

The article deals with the methods of pure breeding, interbreeding ans interspecific hybridization of camels in the conditions of Kazakhstan. 